\title{
Омические контакты к эпитаксиальным структурам CVD-алмаза с дельта-слоями бора
}

\author{
() Е.А. Архипова ${ }^{1}$, Е.В. Демидов ${ }^{1}$, М.Н. Дроздов ${ }^{1}$, С.А. Краев ${ }^{1}$, В.И. Шашкин ${ }^{1}$, М.А. Лобаев ${ }^{2}$, \\ А.Л. Вихарев ${ }^{2}$, А.М. Горбачев ${ }^{2}$, Д.Б. Радищев ${ }^{2}$, В.А. Исаев ${ }^{2}$, С.А. Богданов ${ }^{2}$ \\ ${ }^{1}$ Институт фризики микроструктур Российской академии наук, \\ 607680 Нижний Новгород, Россия \\ ${ }^{2}$ Институт прикладной физики Российской академии наук, \\ 603950 Нижний Новгород, Россия \\ E-mail: suroveginaka@ipmras.ru
}

Поступила в Редакцию 24 апреля 2019 г.

В окончательной редакции 29 апреля 2019 г.

Принята к публикации 29 апреля 2019 г.

Исследуются различные варианты формирования омических контактов к легированным бором $\delta$-слоям, созданным в эпитаксиальных структурах CVD-алмаза. В первом варианте на поверхности алмаза формировался дополнительный тонкий сильно легированный слой, к которому и формировался омический контакт. Затем поверхностный $p^{+}$-слой между контактными площадками стравливался, поэтому протекание тока в структуре происходило только по заглубленному $\delta$-слою. Во втором случае проводился селективный рост сильно легированного алмаза в контактных окнах под маской металла после предварительного травления нелегированного слоя алмаза (сар) до $\delta$-слоя. При этом сильно легированный $p^{+}$-слой будет образовывать торцевой контакт к $\delta$-слою. Эти два варианта отличаются условиями применимости, трудоемкостью технологии изготовления, величиной контактного сопротивления и могут быть использованы для решения задач, в которых требуется различное качество контактов, таких как формирование транзисторных структур или тестовых ячеек для измерения электрофизических характеристик.

Ключевые слова: алмаз, $\delta$-слои, омические контакты, бор.

DOI: $10.21883 /$ FTP.2019.10.48294.40

\section{1. Введение}

В последнее время большой интерес вызывает развитие технологии изготовления монокристаллических пленок алмаза с $\delta$-слоями бора [1-8]. Такие структуры рассматриваются как перспективный полупроводниковый материал с новыми транспортными свойствами. Вопрос формирования омических контактов к таким структурам является очень важным. В настоящее время основными методами создания омических контактов к объемному алмазу $p$-типа являются сильное легирование контактной области атомами бора с концентрацией $>10^{20} \mathrm{~cm}^{-3}[9-12]$ и использование карбидообразующих металлов [13-18]. Сильное легирование позволяет существенно снизить ширину поверхностного барьера и обеспечивает туннельный транспорт носителей через барьер, линейные вольт-амперные характеристика (BAX) и низкую величину контактного сопротивления. Использование карбидообразующих металлов позволяет существенно снизить контактное сопротивление в $10^{3}-10^{4}$ раз для слабо легированного алмаза и в $\sim 10$ раз для сильно легированного $[14,15]$. Кроме того, возникновение карбидов на границе раздела метал-алмаз сильно повышает адгезию контактов к поверхности алмаза.

Прежде всего отметим, что уже в первых работах по формированию омических контактов к алмазу [11] были обнаружены особенности этого материала в сравнении с традиционными полупроводниками $\mathrm{Si}$ и $\mathrm{A}^{\mathrm{III}} \mathrm{B}^{\mathrm{V}}$ (включая их широкозонные соединения), усложняющие известные технологические процессы. Коэффициент диффузии легирующих примесей в алмазе имеет очень низкое значение даже при высоких температурах, отсутствуют сплавы (эвтектики) углерода с более низкой температурой плавления. Распространенным методом формирования контактов остается имплантация ионов бора с последующим высокотемпературным отжигом для устранения структурных дефектов и активации атомов примеси и дальнейшее осаждение слоев металла [12]. Создание сильно легированной области алмаза путем имплантации снижает толщину и эффективную высоту поверхностного барьера и обеспечивает туннельный транспорт носителей через барьер, линейные ВАХ и низкую величину контактного сопротивления. Тем не менее и в этой стандартной для традиционных полупроводников процедуре остается проблема точного выбора температуры и длительности отжига. В работе [12] показано, что в результате имплантации ионов бора с высокой дозой и высокотемпературного отжига возникают процессы аморфизации и графитизации в двух разных областях алмаза - на границе с металлическим контактом и в области максимума выделенной энергии при имплантации. Далеко не всегда удается избавиться от этих областей или по крайней мере уменьшить их толщину. Их последовательное включение приводит к ухудшению контактного сопротивления. Альтернативный вариант формирования металлических контактов к алмазу с высокими механическими, тепловыми и электрическими свойствами был предложен в работах [19]. Этот подход 
использует дополнительную активацию процессов карбидизации кремния на поверхности $\mathrm{Si} /$ алмаз, что позволяет подавить процессы аморфизации и графитизации в контактных областях.

Ясно, что эти особенности формирования омических контактов к структурам алмаза с объемным легированием также проявятся и в случае контактов к структурам с $\delta$-слоями. В данной работе исследуются два подхода по формированию контактов к $\delta$-слоям бора в алмазе, в которых учитываются рассмотренные особенности. В первом на поверхности образца осаждается тонкий $p^{+}$-слой, к которому и формируется омический контакт. По технологии изготовления контактов данный метод является довольно простым. Однако существенным недостатком является сильная зависимость сопротивления контактов от глубины залегания $\delta$-слоя. Если она превышает 15-20 нм, контактное сопротивление сильно возрастает. Второй метод использует селективный рост сильно легированного алмаза в контактных окнах под маской металла с предварительным травлением нелегированного слоя алмаза до $\delta$-слоя. Данный вариант формирования омического контакта является более сложным в сравнении с предыдущим, поскольку требует второго этапа роста сильно легированного алмаза в контактных окнах, однако является более универсальным и подходит для $\delta$-легированных структур с различной глубиной залегания $\delta$-слоя.

Также в работе показана возможность применимости защитной маски из молибдена как для травления, так и для селективного роста алмаза. Кроме того, изучается устойчивость, сплошность маски и вопрос возможного загрязнения поверхности алмаза из материала маски Мо при высокотемпературном росте в окнах.

\section{2. Методика эксперимента}

В работе изучались монокристаллические пленки алмаза с $\delta$-слоями бора, выращенные на монокристаллических подложках фирмы New Diamond Technology. Рост пленок проводился на разработанном в ИПФ РАН CVD-реакторе, в котором в смеси $\mathrm{H}_{2}-\mathrm{CH}_{4}$ излучением магнетрона поддерживалась плазма СВЧ разряда. Для роста $\delta$-слоев газовая смесь кратковременно заменялась на газовую смесь с дибораном $\mathrm{H}_{2}-\mathrm{CH}_{4}-\mathrm{B}_{2} \mathrm{H}_{6}$ [4,5]. Для формирования омических контактов, используя известные из литературы данные по материалу контактов, был выбран состав $\mathrm{Ti} / \mathrm{Mo} / \mathrm{Au}$ с толщинами слоев $\mathrm{Ti}-$ 20 нм, Мо - 30 нм, Au - 100 нм. Напыление отдельных металлических слоев проводилось методом электроннолучевого испарения на установке „АMOD“.

Для травления алмаза с целью вскрытия контактных окон к $\delta$-слою использовалось распыление поверхности алмаза в кислородной плазме также на установке „AMOD“. Давление кислорода в вакуумной камере составляло $10^{-4}$ Торр, ток эмиссии $1.65 \mathrm{~A}$, напряжение разряда $150 \mathrm{~B}$, ток разряда $1.5 \mathrm{~A}$. При используемых технологических параметрах скорость распыления алмаза в кислородной плазме составляла $0.4 \mathrm{Hм} / \mathrm{c}$, развития шероховатости распыляемой поверхности не было зарегистрировано. Также было установлено, что оптимальным материалом маски для травления контактных окон являются пленки молибдена толщиной $\sim 150$ нм. Скорость распыления пленки молибдена в кислородной плазме была значительно ниже, чем материала алмаза. Маска молибдена сохраняла свою целостность и геометрические характеристики вплоть до травления материала алмаза на глубину 1 мкм, что значительно превышает требуемые рабочие параметры.

Контактные сопротивления измерялись методом длинной линии (TLM) с использованием измерительной системы Keithley SCS 4200.

Измерения методом вторично-ионной массспектрометрии (ВИМС) проводились на установке TOF.SIMS-5 с раздельными функциями ионных пучков „распыление-зондирование“. Распыление проводилось ионами $\mathrm{Cs}^{+}$или $\mathrm{O}_{2}^{+}$с энергией 1 кэВ, зондирование ионами $\mathrm{Bi}^{+}$или $\mathrm{Bi}_{3}^{+}$с энергией 25 кэВ. С использованием оптического профилометра Talysurf CCI-2000 были измерены основные геометрические характеристики полученных тестовых структур - перепад высот „Пленка Мо-окно алмаза“, шероховатость поверхности всех материалов и топографический рисунок тестовой структуры.

\section{3. Результаты и обсуждение}

\section{1. Формирование омического контакта с использованием тонкого поверхностного $p^{+}$-слоя}

Были выращены различные структуры с $\delta$-слоями бора на разной глубине от поверхности и тонким поверхностным $p^{+}$-слоем различной толщины. На рис. 1 при-

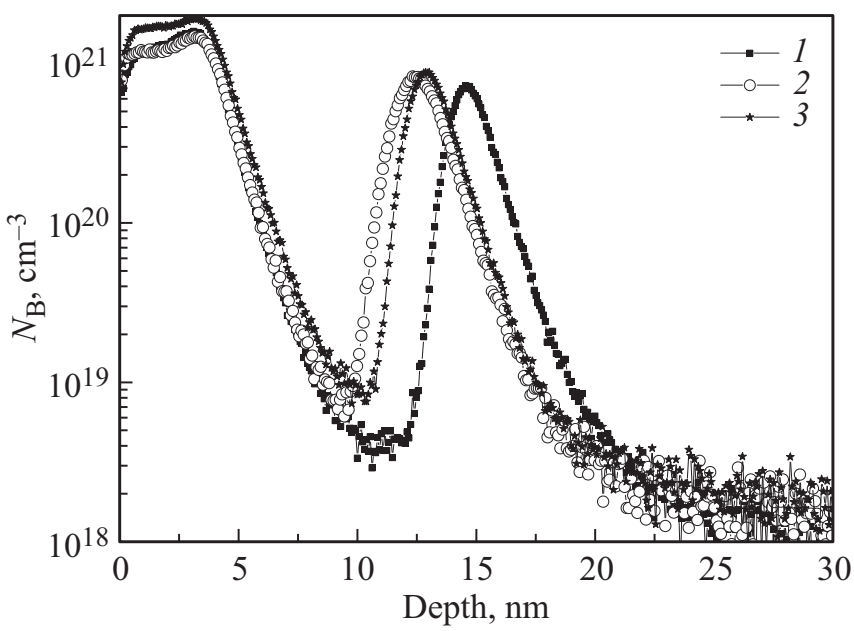

Рис. 1. Профили концентрации атомов бора в структурах с приповерхностным тонким $p^{+}$-слоем и заглубленным $\delta$-слоем: 1 - SS9, 2 - SS10, 3 - SS1-3. 
Контактное сопротивление и удельное сопротивление алмаза

\begin{tabular}{c|c|c|c|c}
\hline \multirow{2}{*}{$\begin{array}{c}\text { № } \\
\text { образца }\end{array}$} & \multicolumn{2}{|c|}{ При наличии верхнего $p^{+}$-слоя } & \multicolumn{2}{|c}{ После стравливания верхнего $p^{+}$-слоя } \\
\cline { 2 - 5 } & $\begin{array}{c}\text { Контактное сопротивление, } \\
\text { Ом } \cdot \text { см }^{2}\end{array}$ & $\begin{array}{c}\text { Сопротивление п/п, } \\
\text { кОм/кв }\end{array}$ & $\begin{array}{c}\text { Контактное сопротивление, } \\
\text { Ом } \cdot \text { см }^{2}\end{array}$ & $\begin{array}{c}\text { Сопротивление п/п, } \\
\text { кОм/кв }\end{array}$ \\
\hline SS10 & $7 \cdot 10^{-7}$ & 4 & $1.1 \cdot 10^{-5}$ & 37 \\
SS1-3 & $7 \cdot 10^{-7}$ & 5.1 & $4.8 \cdot 10^{-4}$ & 36 \\
SS9 & $8 \cdot 10^{-6}$ & 6 & $5 \cdot 10^{-4}$ & 64
\end{tabular}

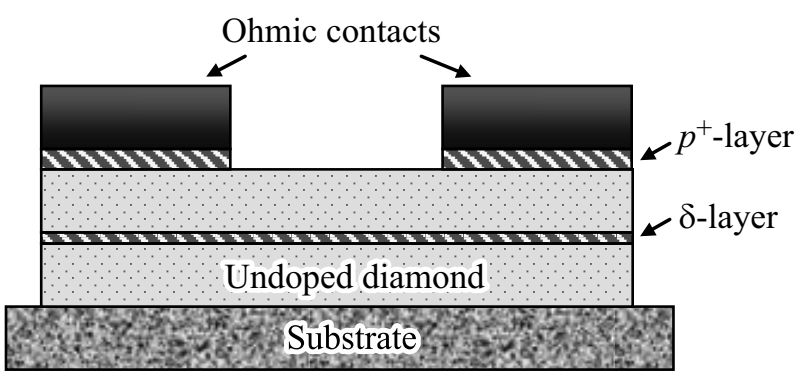

Рис. 2. Схема формирования мезаструктуры и омического контакта к $\delta$-легированным структурам с использованием $p^{+}$-слоя на поверхности.

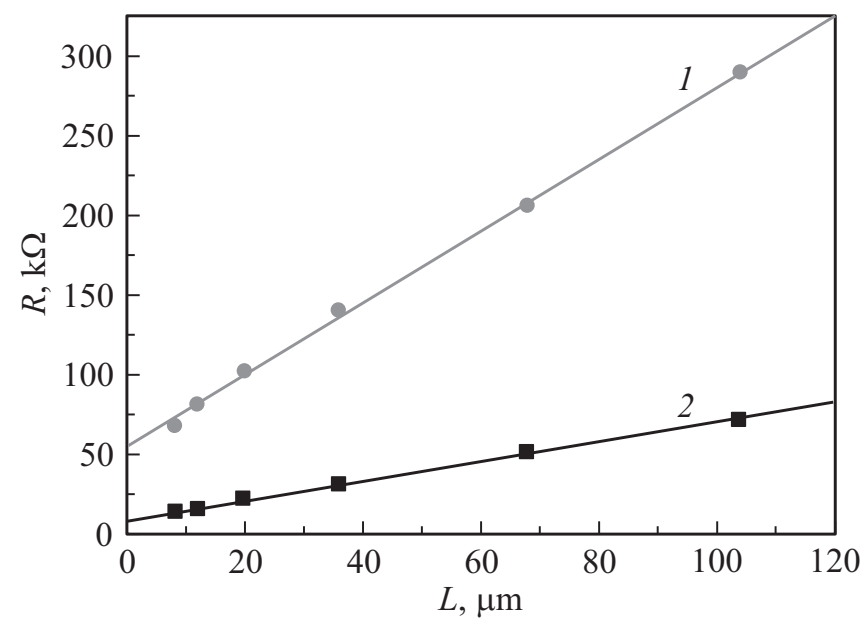

Рис. 3. Результаты измерения контактного сопротивления на линии TLM: 1 - при наличии приповерхностного тонкого $p^{+}$-слоя, $2-$ приповерхностный тонкий $p^{+}$-слой стравлен.

ведены полученные методом ВИМС профили концентрации атомов бора в структурах SS10, SS1-3 и SS9. На этих образцах были сформированы измерительные тестовые ячейки, включая процесс травления мезаструктур. Затем были сформированы омические контакты Ti/Mo/Au.

Омический контакт формировался к $p^{+}$-слою, выращенному на поверхности алмаза. Поверхностный $p^{+}$-слой между контактными площадками стравливался, поэтому протекание тока в структуре происходило только по заглубленному $\delta$-слою. Контакты получились омическими без дополнительного термического отжига.
Схема формирования мезаструктуры и омического контакта показаны на рис. 2.

На рис. 3 показаны результаты измерения контактного сопротивления на линии TLM. Линия 1 измерена для случая, когда в структуре между контактами присутствует приповерхностный $p^{+}$-слой. При измерениях линии 2 верхний $p^{+}$-слой между контактами удален путем травления. Результаты измерения контактного сопротивления и удельного сопротивления алмаза приведены в таблице.

Когда верхний $p^{+}$-слой между контактами стравлен, протекание тока в структуре происходит только по заглубленному $\delta$-слою. Поэтому контактное сопротивление возрастает после стравливания верхнего $p^{+}$-слоя. В таблице также показано, что поверхностный $\delta$-слой не обеднен и обеспечивает эффективный транспорт носителей тока вдоль структуры. Это является еще одной особенностью алмаза - в полупроводниках $\mathrm{Si}$ и $\mathrm{A}^{\mathrm{III}} \mathrm{B}^{\mathrm{V}}$ $\delta$-слой на поверхности будет обеднен носителями.

Контактное сопротивление для образца SS10, находящегося на глубине 12 нм от поверхности алмаза, составило $\rho_{c}=1.1 \cdot 10^{-5} \mathrm{OM} \cdot \mathrm{cm}^{2}$, для SS1-3 на глубине $13 \mathrm{нм}-4.8 \cdot 10^{-4} \mathrm{OM} \cdot \mathrm{cm}^{2}$ и для SS9 на глубине $15 \mathrm{Hм}-5 \cdot 10^{-4} \mathrm{Oм} \cdot \mathrm{cm}^{2}$. Ясно, что наиболее критическим параметром здесь является глубина залегания $\delta$-слоя: чем глубже $\delta$-слой, тем больше сопротивление.

По технологии изготовления контактов данный метод является довольно простым. Однако существенным недостатком является сильная зависимость сопротивления контактов от глубины залегания $\delta$-слоя. Если она превышает 15-20 нм, контактное сопротивление сильно возрастает.

\section{2. Селективный рост сильно легированного алмаза в контактных окнах}

В отличие от предыдущего, второй метод позволяет получить хороший омический контакт в $\delta$-легированных структурах независимо от того, на какой глубине расположен $\delta$-слой.

Предлагаемый метод использует двухстадийный рост алмаза с промежуточными операциями нанесения маски и травления. Предварительно с использованием метода ВИМС изучался профиль легирования и примесный состав переходной границы между отдельными слоями алмаза в условиях двухстадийного роста, так как наличие дополнительных примесей на этой границе может резко повысить контактное сопротивление. 


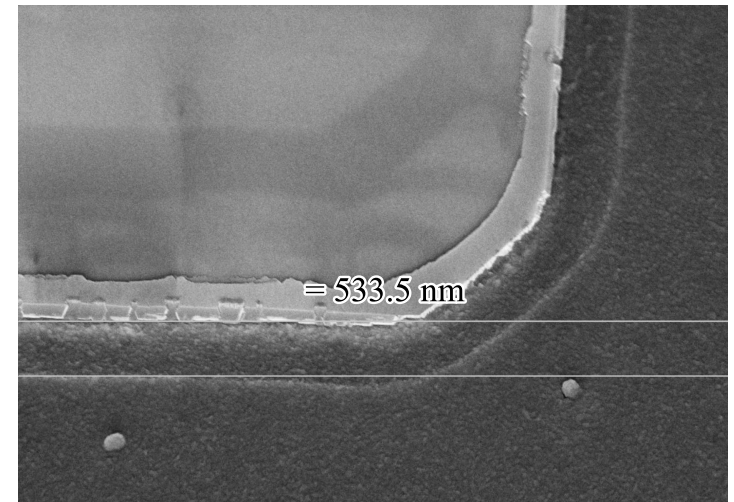

Pис. 4. СЭМ-изображение края контактной области после высокотемпературного роста алмаза под маской молибдена.

По выбранному фотошаблону формировалась маска из молибдена для травления контактных окон в кислородной плазме. Эта же самая маска использовалась и для дальнейшего выращивания $p^{+}$-слоя алмаза в контактных окнах. В структуре, где по данным ВИМС $\delta$-слой расположен на глубине 43 нм, глубина травления алмаза в контактных окнах была выбрана 50 нм, что немного превышает глубину залегания $\delta$-слоя.

Затем проводился рост сильно легированного $p^{+}$-слоя алмаза, при этом была проведена предварительная подготовка поверхности непосредственно в ростовом реакторе. Было показано, что в условиях двухстадийного роста дополнительного загрязнения примесями переходной границы между отдельными слоями алмаза не происходит.

После роста $p^{+}$-слоя алмаза в контактных окнах материал маски удалялся, и проводилось травление мезаструктуры и формирование контактного металлического слоя Ti/Mo/Au. В результате $p^{+}$-слой алмаза будет образовывать торцевой контакт к $\delta$-слою.

С использованием измерительной линии TLM для данного образца было получено контактное сопротивление $R_{\text {cont }}=312$ Ом $\cdot$ мм. Так как омический контакт к $\delta$-слою является торцевым, мы приводим результаты измерений в Ом·мм. Вольт-амперная характеристика омического контакта на этом образце имеет линейный характер в широком диапазоне приложенных напряжений.

Отдельно изучалась устойчивость защитной маски из Мо к процессу дальнейшего высокотемпературного роста сильно легированных слоев алмаза во вскрытых окнах. Также был изучен вопрос - осаждается ли материал алмаза на маску Мо или нет. Эти исследования были необходимы, чтобы выяснить применимость предложенной в работе новой концепции селективного эпитаксиального роста алмаза в контактных окнах.

На рис. 4 показано изображение края контактной области после высокотемпературного роста алмаза в контактных окнах, полученное методом сканирующей электронной микроскопии. Видно, что защитная маска из молибдена не деградировала при высокой температуре роста алмаза в химической активной газовой среде и сохранила свою целостность. Материал алмаза на маску Мо не осаждается либо осаждается в виде отдельных включений поликристаллического алмаза, которые удаляются при последующих процессах литографии вместе с маской Мо. Также можно оценить шероховатость поверхности эпитаксиального алмаза в контактных окнах. Поверхность достаточно гладкая, $S_{q}<1$ нм.

С использованием метода ВИМС был изучен вопрос возможного загрязнения поверхности алмаза из материала маски Мо при высокотемпературном росте в окнах. Основными примесями на поверхности алмаза оказываются щелочные металлы, а также $\mathrm{Cr}$, их концентрация быстро спадает от поверхности ниже 3-5 нм. На поверхности регистрируется незначительное количество примеси Мо с интенсивностью 3-5 импульсов в слое 5 нм. Это соответствует концентрации атомов Мо на уровне $5 \cdot 10^{16}$ ат/см ${ }^{3}$ и не может оказать влияния на поверхностную проводимость алмаза.

Эти исследования показывают применимость предложенной в данной работе концепции селективного эпитаксиального роста алмаза в контактных окнах для создания омических контактов. Отметим также, что указанная выше последовательность металлических слоев обеспечивает хороший омический контакт к слоям алмаза с объемным легированием. Для легирования на уровне $10^{20} \mathrm{aT} / \mathrm{cm}^{3}$ контактное сопротивление составляет $10^{-5}-10^{-6} \mathrm{OM} \cdot \mathrm{cm}^{2}$.

Данный вариант формирования омического контакта требует второго этапа роста сильно легированного алмаза в контактных окнах, однако является более универсальным в сравнении с первым методом и подходит для $\delta$-легированных структур с различной глубиной залегания $\delta$-слоя.

\section{4. Заключение}

Таким образом, в данной работе предложены новые подходы к формированию омических контактов к эпитаксиальным структурам алмаза с $\delta$-слоями бора. Первый подход использует тонкий сильно легированный слой алмаза на поверхности образца, к которому и формируется омический контакт, а протекание тока происходит только по заглубленному $\delta$-слою. Этот способ формирования контактов является достаточно простым, однако может быть использован только для структур, у которых глубина залегания $\delta$-слоя не превышает 50 нм. Второй метод использует селективный рост сильно легированного алмаза в контактных окнах под маской металла с предварительным травлением нелегированного слоя алмаза до $\delta$-слоя. В этом случае получается торцевой омический контакт к $\delta$-слою с низким контактным сопротивлением и линейными ВАХ. Такой метод является более трудоемким из-за сочетания нескольких последовательных этапов роста и постростовой обработки, однако может быть применен для более широкого числа структур, так как не зависит то глубины залегания $\delta$-слоя. 
В работе были получены омические контакты к $\delta$-легированному алмазу с контактными сопротивлениями $10^{-4}-10^{-5} \mathrm{OM} \cdot \mathrm{cm}^{2}$. Отметим, что такие сопротивления являются типичными для контактных сопротивлений к легированным слоям алмаза, известных из литературы.

\section{Финансирование работы}

Технологическая часть работы проводилась при поддержке гранта Российского научного фонда (проект № 17-19-01580). Часть работы, касающейся исследований ВИМС, была поддержана грантом РФФИ 18-0200565. Электрофизические измерения были выполнены в рамках государственного задания ИФМ РАН за 2019 год (тема ГЗ 0030-2019-0021-С-01). В работе использовалось оборудование ЦКП „Физика и технология микро- и наноструктур“.

\section{Конфликт интересов}

Авторы заявляют, что у них нет конфликта интересов.

\section{Список литературы}

[1] G. Chicot, A. Fiori, P. Volpe, T. Tran Thi, J. Gerbedoen, J. Bousquet, M. Alegre, J. Pinero, D. Araujo, F. Jomard, A. Soltani, J. De Jaeger, J. Morse, J. Hartwig, N. Tranchant, C. Mer-Calfati, J. Arnault, J. Delahaye, T. Grenet, D. Eon, F. Omne's, J. Pernot, E. Bustarret. J. Appl. Phys., 116, 083702 (2014).

[2] N. Donato, D. Pagnano, E. Napoli, G. Longobardi, F. Udrea. Diamond Relat. Mater., 78, 73 (2017).

[3] A. Fiori, F. Jomard, T. Teraji, S. Koizumi, J. Isoya, E. Gheeraert, E. Bustarret. Appl. Phys. Express, 6, 045801 (2013).

[4] A.L. Vikharev, A.M. Gorbachev, M.A. Lobaev, A.B. Muchnikov, D.B. Radishev, V.A. Isaev, V.V. Chernov, S.A. Bogdanov, M.N. Drozdov, J.E. Butler. Phys. Status Solidi RRL, 10, 324 (2016).

[5] J.E. Butler, A.L. Vikharev, A.M. Gorbachev, M.A. Lobaev, A.B. Muchnikov, D.B. Radishev, V.A. Isaev, V.V. Chernov, S.A. Bogdanov, M.N. Drozdov, E.V. Demidov, E.A. Surovegina, V.I. Shashkin, A. Davidov, H. Tan, L. Meshi, A.C. Pakpour-Tabrizi, M.-L. Hicks, R.B. Jackman. Phys. Status Solidi RRL, 11, 1600329 (2017).

[6] A. Fiori, F. Jomard, T. Teraji, G. Chicot, E. Bustarret. Thin Sol. Films, 557, 222 (2014).

[7] C. Mer-Calfati, N. Tranchant, P.N. Volpe, F. Jomard, S. Weber, P. Bergonzo, J.C. Arnault. Mater. Lett., 115, 283 (2014).

[8] M. Ogura, H. Kato, T. Makino, H. Okushi, S. Yamasaki. J. Cryst. Growth, 317, 60 (2011).

[9] J.F. Prins. J. Phys. D: Appl. Phys., 22, 1562 (1989).

[10] R. Kalish. Appl. Surf. Sci., 117/118, 558 (1997).

[11] V. Venkatesan, D.M. Malta, K. Das, A.M. Belu. J. Appl. Phys., 74 (2), 1179 (1993).

[12] J.C. Pinero, M.P. Villar, D. Araujo, J. Montserrat, B. Antunez, P. Godignon. Phys. Status Solidi A, 214, 1700230 (2017).

[13] T. Tachibana, B.E. Williams, J.T. Glass. Phys. Rev. B, 45 (20), 11975 (1992).
[14] J. Nakanishi, A. Otsuki, T. Oku, O. Ishiwata, M. Murakami. J. Appl. Phys., 76 (4), 2293 (1994).

[15] M. Yokoba, Yasuo Koide, A. Otsuki, F. Ako, T. Oku, M. Murakami. J. Appl. Phys., 81 (10), 6815 (1997).

[16] P.E. Viljoen, E.S. Lambers, P.H. Holloway. J. Vac. Sci. Technol. B, 12 (5), 2997 (1994).

[17] K.L. Moazed, J.R. Zeidler, M.J. Taylor. J. Appl. Phys., 68 (5), 2246 (1990).

[18] Y. Chen, M. Ogura, S. Yamasaki, H. Okushi. Semicond. Sci. Technol., 20, 860 (2005).

[19] М.П. Духновский, А.К. Ратникова, Ю.Ю. Федоров. Патент РФ, RU2436189 C1, Бюл. № 34 (2011).

Редактор А.Н. Смирнов

\section{Ohmic contacts to CVD diamond with boron doped delta-layers}

\author{
E.A. Arkhipova ${ }^{1}$, E.V. Demidov ${ }^{1}$, M.N. Drozdov' ${ }^{1}$, \\ S.A. Kraev' ${ }^{1}$, V.I. Shashkin ${ }^{1}$, M.A. Lobaev², \\ A.L. Viharev' ${ }^{2}$, A.M. Gorbachev ${ }^{2}$, D.B. Radishchev ${ }^{2}$, \\ V.A. Isaev ${ }^{2}$, S.A. Bogdanov ${ }^{2}$ \\ ${ }^{1}$ Institute for Physics of Microstructures, \\ Russian Academy of Sciences, \\ 607680 Nizhny Novgorod, Russia \\ ${ }^{2}$ Institute of Applied Physics, \\ Russian Academy of Sciences, \\ 603950 Nizhny Novgorod, Russia
}

\begin{abstract}
Various methods of the formation of ohmic contacts to CVD diamond epitaxial structures with boron doped delta layers ( $\delta$-layers) are investigated. In the first approach, an additional thin, heavily doped layer was formed on the surface of the diamond film, to which the ohmic contact was formed. Then, the surface $p^{+}$-layer between the contact pads was etched out, so the current flow in the structure occurred only through the buried $\delta$-layer. In the second approach, doped diamond was selectively grown in contact windows under the mask of metal after preliminary etching the undoped diamond layer (cap) to the $\delta$-layer. In this case, the heavily doped $p^{+}$-layer will form a contact to the $\delta$-layer. These approaches are differs by conditions of applicability, the complexity of manufacturing technology, the value of contact resistance. So they can be used to solve tasks in which different quality of contacts is required, such as the formation of transistor structures or test cells for measuring electrophysical characteristics.
\end{abstract}

